\title{
Vigilância Epidemiológica, Sanitária e em Saúde Pública. A Discussão de Novas Propostas de Reorganização das Estruturas
}

Eliseu Alves Waldman*

A discussão de propostas de implantação de novas estruturas para a área de vigilância epidemiológica deve ser precedida de uma análise mais cuidadosa das experiências de implementação das diversas reformas administrativas da Secretaria Estadual da Saúde de São Paulo, promovidas desde a segunda gestão do Professor Leser (1975-1979). Sem entrar em detalhes, que fugiriam aos objetivos dessa reunião, o que mais nos chama a atenção é que elas nunca foram efetivamente implementadas e, por outro lado, refletiram propostas, muitas vezes, sem coerência entre si, fato que determinou a perda das políticas institucionais de longo prazo determinando, por conseqüência, o enfraquecimento técnico e operacional da Secretaria.

A análise dessa trajetória nos impõe a avaliação do risco da implementação de novas reformas estruturais sem a criação prévia de instrumentos de controle social que garantam políticas de longo prazo, única opção segura para o fortalecimento do Sistema de Saúde. Esse caminho impõe também, propostas menos arrojadas e mais consensuais.

Passando para as questões mais centrais desse painel, vale a pena fazermos um retrospecto da implantação e desenvolvimento da vigilância epidemiológica em nosso Estado. Não restam dúvidas a respeito dos avanços propiciados pela sua utilização, a partir do final da década de 70 . Houve um aprimoramento do sistema de informação a respeito das doenças de notificação compulsória e uma melhor coordenação e agilização das ações de controle dessas doenças, entre outros avanços.

\footnotetext{
* Professor Doutor do Departamento de Epidemiologia da Faculdade de Saúde Pública da USP
} 
No entanto, devemos salientar que, concomitantemente à implantação da vigilância e possivelmente em função da forma pela qual foi implantada em nosso meio, tivemos o rápido desaparecimento dos serviços de epidemiologia da Secretaria Estadual da Saúds.

Neste ponto é oportuno citar Alexandre Languir quando afirmava que não devemos confundir vigilância epidemiológica com epidemiologia pois esta última é muito mais ampla e abrangente e, por outro lado, não devemos também confundir vigilância com ações de controle pois estas constituem atribuição das autoridades locais de saúde.

$\mathrm{Na}$ verdade, de certa forma cometemos os dois equívocos. Ao confundirmos vigilância com epidemiologia desmobilizamos as antigas áreas de epidemiologia da Secretaria da Saúde e ao equivocadamente entendermos vigilância como sinônimo de ações de controle, induzimos o órgão de vigilância a assumir a coordenação das ações de controle de doenças transmissíveis. Sucede que o controle dessas doenças, especialmente aquelas que, com alguma freqüência, apresentam-se sob a forma epidêmica na comunidade, constituem necessidades sentidas da população e dos profissionais de saúde e, portanto, consomem todo o tempo e recursos disponíveis pelo órgão e pelas equipes que nele trabalham. Em decorrência, tivemos também a incorporação de concepções mais restritas de vigilância epidemiológica e, portanto, deixamos de utilizar boa parte de seu potencial.

Ao buscarmos novos caminhos com vistas ao aprimoramento do Sistema Único de Saúde devemos levar em conta os ensinamentos oferecidos por essas experiências. Primeiro, não devemos enfraquecer, mais ainda, a estrutura dos órgãos que permanecerão na Secretaria da Saúde, uma vez concluído o processo de municipalização, sem antes termos elaborado propostas de longo prazo para a Secretaria como um todo, com objetivos bem definidos; com delimitação clara de instrumentos a serem utilizados; com política de formação, recrutamento e reciclagem de pessoal e com carreiras bem estruturadas. $\mathrm{O}$ mesmo ocorrendo, num segundo momento, com os órgãos que a comporão. Concomitantemente, devemos pactuar mecanismos sociais que garantam que os recursos públicos aplicados nessa reorganização, não sejam perdidos pela interrupção do processo. Em segundo lugar, devemos reorganizar a área de epidemiologia, situando a vigilância como parte dela, de forma a permitir que a Secretaria esteja instrumentalizada não só para agilizar e aprimorar as ações de controle, mas também para estabelecer políticas para o setor saúde. Em terceiro lugar, definir qual será o papel reservado à pesquisa como prática interna do SUS, pois seu grau de auto-sustentação estará condicionado a essa definição.

Um aspecto porém não deve ser esquecido. A implantação do SUS, com a descentralização dos serviços de saúde ao nível dos municípios, será um pro- 
cesso lento, com uma trajetória de, talvez, 15 a 20 anos. Esse longo período implica numa transição responsável, na qual a Secretaria Estadual se obrigará a manter, de forma organizada, uma estrutura voltada a implementação de ações de controle de doenças, enquanto os municípios não possam assumi-las. Deverá estar ciente também, que algumas atividades de controle, possivelmente nunca possam ser completamente descentralizadas, face a suas peculiaridades, como é o caso de algumas ações voltadas ao controle de vetores. Essa estrutura ou órgão, com as ressalvas feitas, deverá ter caráter obrigatoriamente transitório.

A implantação do SUS e a conseqüente descentralização dos serviços ao nível dos municípios, oferece oportunidades não só para a reorganização da área de epidemiologia na esfera da Secretaria Estadual de Saúde, como também para a incorporação de concepções mais amplas da vigilância epidemiológica, ou seja, como instrumento voltado ao estabelecimento das bases técnicas das ações de controle. Essa concepção torna a vigilância o elo de ligação entre os serviços de saúde e a pesquisa como prática de saúde pública (aquela implementada no interior do Sistema de Saúde). Em outros termos, a vigilância ao acompanhar e analisar sistematicamente o comportamento das doenças na comunidade com fundamento no conhecimento científico disponível, deverá identificar lacunas no conhecimento, induzir a pesquisa e, finalmente, incorporar o novo conhecimento produzido, garantindo o aprimoramento dos serviços de saúde.

Neste ponto vale a pena comentar quais seriam os motivos de, em nosso meio, primeiro implantarmos os programas de saúde e somente em seguida um sistema de vigilância correspondente, quando seria de se esperar o contrário. Esse fato decorre de termos um Sistema de Saúde de baixa capacidade de resolutibilidade, dependente da incorporação de "pacotes tecnológicos" produzidos por organismos internacionais, resultado da quase inexistência de um sub-sistema de pesquisa no interior do Sistema de Saúde.

O SUS para atingir um mínimo de auto-sustentação, deverá fortalecer o desenvolvimento da pesquisa em seu interior, a semelhança do que fizeram todos os países cujos sistemas de saúde alcançaram bom desempenho, inclusive países do terceiro mundo, como é o caso de Cuba.

As definições relativas ao grau de auto-sustentação do SUS e da abrangência com que utilizaremos a vigilância como instrumento de saúde, condicionarão as políticas a serem implementadas pelos Institutos de Pesquisa e, em particular dos Laboratórios de Saúde Pública.

Outro aspecto que merece especial atenção, é a necessidade de uma delimitação precisa de quais campos da saúde pública serão objeto de atuação dos órgãos que no Brasil receberam a denominação de Vigilância Sanitária, assim como quais instrumento utilizarão (por exemplo: fiscalização sanitária, vigi- 
lância epidemiológica, monitorização, pesquisa experimental, pesquisa epidemiológica, educação sanitária, etc.). Essa definição é indispensável porque a área de abrangência desses órgãos é estratégica para a saúde pública em regiões industrializadas, como é o caso do Estado de São Paulo.

Por fim cabem algumas considerações a respeito do que vem ser Vigilância à Saúde. Essa denominação tem sido freqüentemente utilizada para designar algumas experiências municipais, de gerência de serviços de saúde, com especial ênfase, não só à assistência integral à saúde, mas também às condições de vida da população, portanto, dentro de um espectro ideológico bem delimitado. No entanto, como instrumento de saúde pública, a vigilância à saúde não está ainda bem definido, podendo ser entendida, porém, como uma proposta de utilização rotineira da monitorização de indicadores de saúde, econômicos e sociais com o objetivo de estabelecer prioridades e políticas para o setor saúde. Em outros termos a retomada da ampla utilização da epidemiologia na prática sanitária. 